apparatus was clesigned by $\mathrm{Mr}$. Whitehead, the inventor of the celebrated torpedo, and is said to have worked satisfactorily.

A CORRESPONDENT writes to us that in looking throngh some of the drawings and prints, \&c., of Old London, belonging to Mr. J. E. Gardner, F.S.A., of Parls House, he came upon the following interesting handbill :-

$$
\begin{aligned}
& \text { Proposals } \\
& \text { for a }
\end{aligned}
$$

Short course of lectures

$$
\begin{gathered}
\text { on } \\
\text { Fossils } \\
\text { by }
\end{gathered}
$$

Emanuel Mendes da Costa.

The course will consist of only

TWELVE LECTURES.

A public Introductory lecture will be given gratis to any one who chuse to come.

To begin on Wednesday, 7 June, at noon, at the Author's appartments at a shoemaker's opposite Arundel Street in the Strand and the futture Lecture Hours will be determined by the subscribers.

The conditions are

One Guinea the course.

To be paid on Subscribing.

Single lectures at two shillings and sixpence each.

Subscriptions are taken in at Mr. Elmsley's, Bookseller, opposite Southampton. St., Strand; Mr. White, bookseller in Fleet-street; Mr. Humphreys, dealer in shells and other curiosities in St. Martin's Lane, near Charing Cross ; and by the author at his said appartiments.

N.B.-The Introductory lecture will be repeated on Thursday evening at six o'clock.

Ir is proposed to hold an anthropological exhibition at Moscow in the coming summer, together with a general meeting of anthropologists from all parts of the world.

WE have on our table the following worls:-_"History of the Stsam Engine," R. H. Thurston, Kegan Paul and Co.; "Études et Lectures sur l'Astronomie," Camille Flammarion, G. Villars, Paris ; "Catalogue des Étoiles Doubles et Multiples," Camille Flammarion, G. Villars, Paris; "Sport and Work on the Nepaul Frontier," "Maori," Macmillan and Co. ; "Mathematical Problems," J. Wolstenholme, Macnillan and Co.; "The Fairy-Land of Science," Arabella B. Buckley, E. Stanford; "Das Leben," Philipp Spiller, Gerstmann, Eerlin; "Wanderings in Patagonia," Julius Beerbohm, Chatto and Windus; "Natural History of Victoria," Frederick McCoy, Tribner; "Fourth Annual Report of the Imperial Mint;" "Extra Physics and the Mystery of Creation," Hodder and Stoughton; "From Kulja Across the Tian Shan to Lob Nor," Col. N. Prejevalsky, Sampson Low and Co.; "The Heart of Africa," Dr. Georg Schweinfurth, Sampson I-ow and Co,; "The Philosophy of Science, Experience, and Revelation," John Coutts, F. Pitman; "The Native Flowers and Ferns of the United States," Parts 13, 14, 15, 16, Thomas Mechan, L. Prangola, Boston; "The Principles of Light and Colour," Edwin B. Bazbitt, Truibner and Co.

THE additions to the Zoological Society's Gardens during the past week include a White-whiskered Paradoxure (Paradoxurzls leucomystax) from East India, presented by Mr. W. G. Wilson; a Common Barn Ox1 (Strix flammea), British, presented by Mr. W. Davies; a Common Coot (Fulica atra), British, presented by Mr. F. H. O'Donoghue; two Philantomba Antelopes (Cephalophus maxivelli) from West Africa, two Egyptian Jerboas (Dipzts agyptius) from Egypt, purchased; three River Jack Vipers (Vipera rhinoceros) from West Africa, deposited.

\section{CIRCULATING DECIMALS}

THE properties of circulating decimals mentioned by $\mathrm{Mr}$. $R$. Chartres and by Mr. E. P. Toy in NATURE (vol. xviii. pp. 29I, 54I) are particular cases of very general laws relating to the periods of circulating decimals of which, as they are net stated with any approach to completeness in any work on arithmetic with which I am acquainted, it may be worth while to give a brief explanation.

Consider the process of converting a valgar fraction into a circulating decimal; take for example $\frac{1}{3}$. The work is-

39) I.00 (.02564i
$\frac{78}{220}$
$\frac{195}{250}$
$\frac{234}{160}$
$\frac{156}{40}$
$\frac{39}{10}$.

which may be more concisely and better arranged thus :-

$$
\text { 39) } \begin{array}{rr}
\text { I } & (\cdot \dot{0} \\
10 & 2 \\
22 & 5 \\
25 & 6 \\
16 & 4 \\
4 & \dot{1}
\end{array}
$$

ro, 22, 25, I6, 4 being the remainders and the corresponding quotient ngures being written at the side. From this it is clear

\begin{tabular}{|c|c|c|}
\hline 39) $2(\cdot 0$ & 39) $381 \cdot$ & 39) $37(.9$ \\
\hline 205 & 297 & 194 \\
\hline 5 I & 174 & 34 \\
\hline II 2 & 143 & 28 \\
\hline 328 & 235 & 7 \\
\hline$\delta \dot{2}$ & 358 & $3 I$ \\
\hline
\end{tabular}
that -

$$
\begin{aligned}
& \frac{1}{35}=\cdot \dot{0} 2564 \dot{1}, \frac{10}{3}=\cdot \dot{2} 5641 \dot{0}, \frac{2}{3}=\cdot \dot{5} 6410 \dot{2}, \frac{25}{3}=\dot{6} 4102 \dot{5} \text {, } \\
& \frac{1}{3} \frac{\dot{6}}{5}=\dot{4} 1025 \dot{6}, \frac{4}{35}=\cdot \dot{10256 \dot{4},}
\end{aligned}
$$

and the numbers $I, 10,22,25,16,4$ form a cycie such that if we clivide any one of them by 39 we obtain the others as re. mainders in this order, and all the fractions give rise to the same period, though the beginning is macle in ench case at a different place in the period.

The following are three other divisions arranged in the same manner :-

The four divisions thits give the values of the periods of the fractions $\frac{1}{35}, \frac{2}{35}, \frac{4}{35}, \frac{5}{3}, \ldots \ldots \frac{78}{3} \frac{8}{3}, i . t^{*}$, of all the proper fractions in their lowest terms, having 39 as denominator. In this case, therefore, there are four distinct periods, or, say, four periods each containing six figures; one of these, viz., that to which $\frac{\pi}{3}$ belongs, may be called the leading period.

In general if $q$ be any number prime to ro, and if all the proper fractions in their lowest terms having $q$ for denominator be converted into decimals there will be $f$ periods each contain. $a$ digits, and $a$ and $f$ will be connected by the relation $a f=\phi(q)$, where $\phi(q)$ denotes the number of numbers less than $q$ and prime to it. If $q$ be a prime, $\phi(q)=q-\mathbf{r}$.

It is to be observed that if we divide $r$ and $q-r$ respectively by $q$ the digits of the periods will in the two cases be complementary, i.e., the sum of each corresponding pair will be 9. Thas in the case of 39

$$
\begin{array}{ll}
\frac{1}{3 y}=\dot{0} 2554 \dot{i} & \frac{2}{30}=\dot{0} 5128 \dot{z} \\
\frac{38}{3 v}=\dot{9} 7435 \dot{8} & \frac{37}{30}=\dot{9} 4871 \dot{7}
\end{array}
$$

and $9+0=9,7+2=9$, Sc. Also, the sum of each pair ot corresponding remainders is $q$; e.g., in the divisions for $\frac{1}{3} g$ and $\frac{58}{3}, \frac{2}{3} \frac{2}{5}$ and $\frac{37}{3}$, the sum of each pair of corresponding remainders is 39 .

If, as in the case of 39 , the remainder $q$ - I does not beloing to the leading period, the periods may be arranged in pairs, the periods in each pair being complementary to one another. If 
the remainder $q-$ I dees belong to the leading period, each pericd will contain an even number of digits, and the first haif and second half of each period will be complementary. Thus, for $q=73$ there are nine pexiods: ò $36986 \dot{3}$, ó273 972 $\dot{6}_{\text {, }}$ $\dot{0}_{4} 109580^{\circ}$, \&c., and in each the two ha!ves are complementary. If there is but one period corresponding to $q$, of course the remainder $q$ - 1 must belong to this period, so that in this case the two halves are always complementary. Returning to the period of $\frac{1}{39}$, we see that it is such that if we multiply it by 4 we obtain the same period, only beginning with the last digit, that if we multiply it by 16 we obtain the same period beginning with the last digit but one, and so on. Thus, from knowing that the last figure of the period is $r$, and that the last remainder is 4 , we can obtain the period; for $4 \times x=4$ so that the last figure but one must be 4 , the last two figures must therefore be $4 \mathrm{I}$, multiply this by 4 we have 164 , so that the previous digit must be 6 , and so on. This process amounts to multiplying the I by 4 , multiplying the 4 by 4 , giving 6 and 1 over, multiplying the 6 by 4 and adding the $\mathrm{I}$, giving 25 , i.e. 5 with 2 over, and so on, until the period is completed.

In general, in converting $\frac{\mathbf{I}}{q}$ into a circulating decimal, if $k$ be the last digit of the period, and $r$ the last remainder $10 r-\mathbf{I}=k q$, so that the last remainder $=\frac{1}{10}(k q+1)$ and $k=9,3,7$ or 1 according as $q$ ends in $1,3,7$, or 9 . This is, in fact, the property mentioned by Mr. Chartres and Mr. Toy; the class of relations to which it belongs, and the reason for their existence, is evident from what has been said above.

The most direct manner in which the foregoing principies can be applied to abbreviate the labour of division does not consist in multiplying the digits by the remainder from the end but from the beginning. For example, in finding the decimal equi. valent to $\frac{x}{17}$ the first four digits are 0588 and the remainder is 4 ; therefore $\frac{1}{17}=0588_{17}^{4}$, multiplying by 4 , we have $\frac{4}{17}=$ $23521 \%$ whence ${ }_{11}^{1}=05882352 \frac{16}{17}$; we could then find the next four digits by multiplying the four digits last found by 4 and reducing the fraction $i \frac{4}{1}=3 \frac{13}{1}$, so that the next mul. tiplication would be a multiplication of the whole period already found by $\mathrm{I}_{3}$; but as in this case the remainder does not recur after eight digits (if it did recur after eight digits the remainder would be $\frac{1}{17}$ not $\left.\frac{1}{1} \frac{6}{7}\right)$, it must consist of sixteen digits, and the next eight are the complements of the first eight, and are therefore 94 I 17647 .

The principle of the method is to continue the division till a relatively small remainder occurs and then to multiply the figures already found by this remainder, and so on continually till all the figures are obtained. This is the method that has been generally employed in finding the reciprocals of large numbers when the whole period was required. There are several points to be attended to in order that the process may be simplified as much as possible, but these I pass over. The greatest saving of labour afforded by the principle is when a 5 or 2 occurs as remainder early in the division, as then we obtain all the remaining digits as fast as the hand can write them by division by 2 or 5 in the respective cases, without the occurrence of any fractions. Thus, for example,

$$
\frac{1}{61}=\cdot 0 \dot{0} 639344262295
$$

$0819672131147540983606557377049180327868852459^{\circ}$

if we perform the division till we come to the quotient digit 5 we then have a 5 remainder, and all the other digits are obtained by halving the figures from the commencement, viz., $1639 . .$. The quotient can also be completed rapidly by division whenever a remainder occurs that is a submultiple of one that has previously occurred. Thus in the case of $\frac{x}{6}$, the remainder after the first 6 is 24 and after the first 8 is 12 , so that the figures that follow the 8 , viz., $1967 . \ldots$, are obtained at once by halving those that follow the 6 , viz., 3934 . . .

In the Messenger of Mathematics for April, 1878, I pablished the following note:-

"Write down a 5 , divide it by 2 giving 2 with I over, divide 12 by 2 giving 6 , divide 6 by 2 giving 3 , divide 3 by 2 giving $I$ with I over, divide I I by 2 giving 5 with I over, divide I 5 by 2 giving 7 with $\mathbf{I}$ over, and so on till the figures repeat. We thus obtain the figures $5263157894736842 \mathrm{r}$, and these with a cipher prefixed are the period of $\frac{1}{19}$, viz.-

$$
x_{1 y}^{x}=\cdot \dot{0} 5263157894736842 \mathrm{i} \text {. }
$$

"If we start with 50 and halve in the same manner, prefixing two ciphers, we obtain the period of $\frac{1}{x y}$, viz.-

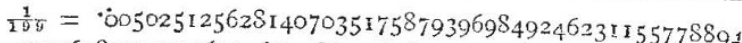
472361809045226130653266331658291459286432160804020 i.

"Similarly, if we start with 500 and halve as before, we obtain, after prefixing three ciphers,- -

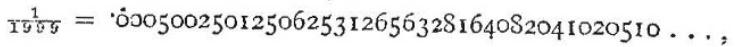
and, generally, the process gives the reciprocal of I followed by any number of 9 's.

"If we start with 20, 200, $2000, \& \mathrm{c}$., and divide continually by 5 instead of by 2 , prefixing one, two, three, $\&$ c., ciphere, we obtain the periods of the reciprocals of $49,499,4999, \ldots$ For example,-



${ }^{4} \frac{1}{45}={ }^{\circ} 020040080160320641282565130260521042084 \ldots \ldots$

"The process is very expeditious, the figures of the periods being obtained as fast as the hand can write them."

The results stated in this note were obtained as follows: the object was to find the divisors for which the first remainder was 5 , so that the halving should begin from the first significant figure; these numbers are seen at once to be $19,199,1999 \ldots$ Similarly the first remainder is 2 for the divisors $49,499,4999 \ldots$ It should be mentioned that these are particular cases of $\mathrm{Mr}$. Suffield's method of synthetic division.

If $q$ be prime and there be only one period corresponding to $q$ (as is the case for $q=7,17,19,23,29,47,49,59,61,97$, \&c.), the $q$ - $\mathrm{I}$ fractions $\frac{\mathbf{I}}{q}, \frac{2}{q}, \ldots \frac{q-\mathbf{I}}{q}$ have all the same period, viz., the $q-\mathbf{I}$ digits that form the period of $\frac{\mathbf{I}}{q}$ are such, that if we multiply them by $2,3,4,5 \ldots q-\mathrm{r}$, we always reproduce these same digits in the same cyclical order, but begimning at a different place. The case of the period of 7 , viz., I 42857 , which is such that, multiplying it by 2 , we have 285714 , by 3 we have 428571 , \&c., is well lnown, and is often given as a puzzle; but the general result is a very remarkable one, e.g., it is remarkable that it should be possible to write duwn 96 digits, such that their first 96 multiples should consist of the same digits in the same cyclical order. In the foregoing remarks I have confined myself entirely to the statement of the principles connected with the results referred to in NATURE, and to those which arise directly from them.

\section{IJ. W. L. GLAISHER}

\section{SCIENTIFIC SERIALS}

American Fournal of Science and Arts, December, 1878.-In the opening paper Gen. Warren considers that the Minnesota Valley and the Mississippi Valley above the Ohio have been, as a rule, formed since the deposition of the glacial drift, which exists in the banlis of the river, and that the Winnipeg basin drained out southward along it; aIso, that the loess deposits extending up to the neighbourhood of Savannah are later than the last glacial drift, \&c. The hypothesis of southern elevation and northern depression (probably reversed sometimes and repeated) is relied on to explain the effects.-Prof. Dana, continuing his valuable paper on some points in lithology, contend; for basing distinction in kinds of rocks on difference in chemical and mineral constitution as regards chief constituents, and offers a classification in eight divisions. - The principle that when the entropy of any isolated material system has reached a maximum the system is in a state of equilibrium, is developed by $\mathrm{Mr}$. Gibbs as a foundation for the general theory of thermodynamic equilibrium.-Mr. McGee distinguishes crania of the mound-builders of the Mississippi Valley from those of modern Indians by a greater development of the posterior molars.-An interesting paper by the Rev. C. Hovey, on discoveries in western caves, describes, inter alia, the remarkable acoustic properties of Echo River passage-way (in the Mammoth Cave), where a strong vocal impulse is prolonged with sustained vigour for fifteen seconds or more; also a locality discovered last April in the Wyandot Cave, in which "pits, miry banks, huge rocks, are overhung by galleries of creamy stalactites, vermicular tubes intertwined, frozen cataracts, and all, in short, that nature could do in her wildest and most fantastic mood." There is a row of musical stalactites, very broad and thin, on which a chord can be struck, or a melody played by a skilful hand.-Prof. Harrington analyses the Chinese official almanac, issued annually in Decem- 